\title{
Quality of life assessment in males with androgenetic alopecia - a prospective study
}

\section{Mrinal Gupta}

\author{
Department of Dermatology, Treatwell Skin Centre, Jammu and Kashmir, India
}

Corresponding author: Dr. Mrinal Gupta, E-mail: drmrinalgupta@yahoo.com

\begin{abstract}
Background: Androgenetic alopecia (AGA) is a common hair loss disorder with genetic predisposition seen commonly in men. Even though the condition is harmless, non-life threatening but it causes a significant amount of psychological stress and affects the individual's overall quality of life (QoL). Objectives: This study was carried out to assess the QoL in patients with AGA using the Dermatology Life Quality Index (DLQI) questionnaire. Methods: A total of 100 male AGA patients were enrolled in this study, and DLQI was used to evaluate the QoL of the patients. The DLQI uses 10 items regarding symptoms and feelings, daily activities, leisure, work and school, personal relationships, and treatment as dimensions of life, each scored on a 0-3 scale. The total DLQI score equals 0-30; higher scores showing greater impact on QoL. Results: The study population comprised of 100 males aged between 19 to 58 years with a mean age of $28.3 \pm 6.4$ years. DLQI scores ranged from 2 to 21 with a mean score of 5.28. Higher DLQI scores were observed in younger patients and in patients with a long standing disease, as well as in patients with higher education and in unmarried population. Higher scores were obtained for questions pertaining to self image perception and social interaction impairment. Conclusion: Patients with AGA have a significantly decreased quality of life. A higher DLQI score was seen in younger age, long standing hair loss and in severe grades of alopecia. AGA is associated with a lowered self esteem.
\end{abstract}

Key words: Androgenetic alopecia, Quality of life; DLQI

\section{INTRODUCTION}

Androgenetic alopecia (AGA) is considered to be the most common type of baldness characterized by progressive hair loss in genetically predisposed individuals. The prevalence rates among general population have been shown to range from $14 \%$ to $58 \%$, with a tendency to increase with age [1]. Although AGA is a relatively benign dermatological condition, but as hair is an important component of identity and self image, patients with AGA may experience a distorted body image and negative feelings. Various studies have demonstrated that AGA can have a significant negative impact on the quality of life of the affected persons and even clinically imperceptible hair loss has been correlated with a decreased quality of life $[2,3]$. One of the most important psychological aspects related to AGA is related to the true or imagined perceptions of others. Few studies have reported that the QoL of patients with hair loss was lower than that of patients with cardiovascular disease, diabetes, and cancer [4]. Therefore, it is very important to understand the impact of alopecia on the QoL of patients while assessing its severity.

This study was carried out to assess the QoL in patients with AGA and its association with duration, age of onset and severity.

\section{MATERIALS AND METHODS}

This was a prospective study carried out over a period of one year in our centre in which one hundred male patients aged $>18$ years with AGA were included. Patients with severe seborrheic dermatitis, alopecic disease, except for androgenic alopecia, and scalp 
disorders, such as scalp psoriasis and infection were excluded. All the patients were otherwise mentally and physically healthy and provided written informed consent before participation.

All the patients were evaluated and details like age of onset, duration of disease, severity grading of alopecia was done and details recorded in a structured proforma. The DLQI questionnaire consisted of 10 questions regarding symptoms and feelings, daily activities, leisure, work and school, personal relationships, and treatment as dimensions of life. Each item was scored on a scale of $0-3$ points. Scores were added to yield a total DLQI of 0-30 points; higher scores indicated greater impact on the patient's QoL (Table 1).

The patient's alopecia severity was graded on the basis of Norwood's classification as mild (Grade I and II), moderate (Grade III and IV) and severe (Grade V, VI and VII) [5].

\section{RESULTS}

The study population comprised of 100 males aged between 19 to 58 years with a mean age of $28.3 \pm 6.4$ years with 40 patients having mild, 32 having moderate and 28 having severe alopecia. Among the study population, the DLQI scores ranged from 2 to 21 with a mean score of 5.28. Hair loss had the maximum impact on the self esteem and social interaction as seen from the total DLQI scores which were much higher for Questions 2, 3 and 5 (Fig. 1). It was observed that the DLQI score was related to various clinical characteristics as a higher score was seen in younger patients and in patients with a long standing disease. DLQI scores were also related to the educational and marital status as higher scores were observed in patients with higher education and in unmarried population. The clinical characteristics of the study population are shown in Table 2. Patients with moderate or severe hair loss had significant impairment of self esteem as higher scores were observed in these groups in questions related to social interactions and self image perception (Fig. 2).

\section{DISCUSSION}

Hair has a significant role in the overall appearance of the person which has various social and interpersonal implications. In the sociocultural context, hair has been given a lot of importance and abundant hair has symbolized vitality, health, and virility, whereas loss or removal of hair can connote subjugation, loss of individuality, impotency, and/or decrepitude. Hair quality and appearance can be an indicator of attractiveness and sexuality for many people, and visible hair loss can have a major negative impact. Hair loss significantly impacts an individual's self image, and studies indicate that patients with hair loss may have significantly decreased quality of life. Quality of life is defined as the subjective perception of the impact on the health status and on the physical, psychological, and social functioning and well-being of the patients. Quality of life assessments help, in clinical practice, clinicians to make judgments about which aspects of daily life are most affected by the disease.

In our study, the mean DLQI score was 5.28 which are comparable to the score of $6.3 \pm 6.3$ reported by Zhang et al in 178 patients of AGA [4]. Williamson et al also reported a mean score of $8.3 \pm 5.6$ in 70 patients with alopecia [6]. Our study showed that AGA moderately affected the QoL, including feelings of loss of selfconfidence and low self-esteem. In our study, higher scores were recorded for questions 2, 3 and 5 in the questionnaire which reflected the significant lowered self esteem and self perception of one's appearance due to hair loss and hence the impaired social well being of the patients. We observed higher DLQI scores in younger patients, patients with long standing hair loss and in higher grades of alopecia. These results are in accordance with the findings by Han et al who also reported that younger patients, patients with long standing and severe alopecia experienced more psychosocial impairment and substantial distress [7]. Zhang et al also reported higher DLQI scores in younger age group, long standing disease and in severe grades of alopecia [4].

Numerous studies have shown that women with hair loss experience increased self-consciousness, feelings of unattractiveness, social withdrawal, emotional stress, low

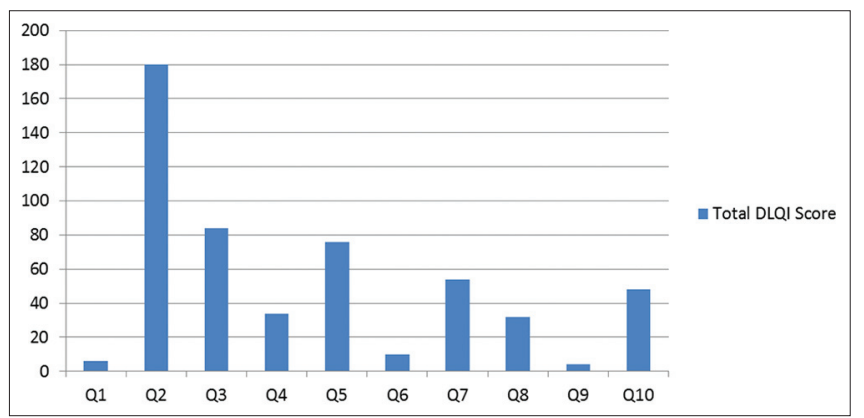

Figure 1 :Total DLQI score for the 10 questions. (DLQI - Dermatology Life Quality Index) 
Table 1: The Dermatology Life Quality Index

\begin{tabular}{|c|c|c|c|}
\hline \multicolumn{4}{|c|}{ DERMATOLOGY LIFE QUALITY INDEX } \\
\hline Hospital No: & \multicolumn{3}{|l|}{ Date: } \\
\hline Name: & \multicolumn{3}{|l|}{ Score: } \\
\hline Address: & \multicolumn{3}{|c|}{ Diagnosis: } \\
\hline \multicolumn{4}{|c|}{$\begin{array}{l}\text { The aim of this questionnaire is to measure how much your skin problem has affected your life OVER TH } \\
\text { tick } \checkmark \text { one box for each question }\end{array}$} \\
\hline \multirow{4}{*}{$\begin{array}{l}\text { 1. Over the last week, how itchy, } \\
\text { sore, painful or stinging has your } \\
\text { skinbeen? }\end{array}$} & Very much & $\square$ & \\
\hline & A lot & $\square$ & \\
\hline & A little & $\square$ & \\
\hline & Not at all & $\square$ & \\
\hline \multirow{4}{*}{$\begin{array}{l}\text { 2. Over the last week, how } \\
\text { embarrassed or self conscious } \\
\text { have you been because of your } \\
\text { skin? }\end{array}$} & Very much & $\square$ & \\
\hline & A lot & $\square$ & \\
\hline & A little & $\square$ & \\
\hline & Not at all & $\square$ & \\
\hline \multirow{4}{*}{$\begin{array}{l}\text { 3. Over the last week, how much } \\
\text { has your skin interfered with you } \\
\text { going shopping or looking after } \\
\text { your home orgarden? }\end{array}$} & Very much & $\square$ & \\
\hline & A lot & $\square$ & \\
\hline & A little & $\square$ & \\
\hline & Not at all & $\square$ & Not relevant $\square$ \\
\hline \multirow{4}{*}{$\begin{array}{l}\text { 4. Over the last week, how much } \\
\text { has your skin influenced the } \\
\text { clothes you wear? }\end{array}$} & Very much & $\square$ & \\
\hline & A lot & 口 & \\
\hline & A little & $\square$ & \\
\hline & Not at all & $\square$ & Not relevant $\square$ \\
\hline \multirow{4}{*}{$\begin{array}{l}\text { 5. Over the last week, how much } \\
\text { has your skin affected any social or } \\
\text { leisure activities? }\end{array}$} & Very much & $\square$ & \\
\hline & A lot & $\square$ & \\
\hline & A little & $\square$ & \\
\hline & Not at all & $\square$ & Not relevant $\square$ \\
\hline \multirow{4}{*}{$\begin{array}{l}\text { 6. Over the last week, how much } \\
\text { has your skin made it difficult for } \\
\text { you to do any sport? }\end{array}$} & Very much & $\square$ & \\
\hline & A lot & $\square$ & \\
\hline & A little & $\square$ & \\
\hline & Not at all & $\square$ & Not relevant $\square$ \\
\hline \multirow{5}{*}{$\begin{array}{l}\text { 7. Over the last week, has your } \\
\text { skin prevented you from working or } \\
\text { studying? } \\
\text { If "No", over the last week how } \\
\text { much has your skin been a } \\
\text { problem at work or studying? }\end{array}$} & Yes & $\square$ & \\
\hline & No & & Not relevant $\square$ \\
\hline & A lot & $\square$ & \\
\hline & A little & $\square$ & \\
\hline & Not at all & $\square$ & \\
\hline \multirow{4}{*}{$\begin{array}{l}\text { 8. Over the last week, how much } \\
\text { has your skin created problems } \\
\text { with your partner or any of your } \\
\text { close friendsor relatives? }\end{array}$} & Very much & $\square$ & \\
\hline & A lot & & \\
\hline & A little & $\square$ & \\
\hline & Not at all & $\square$ & Not relevant $\square$ \\
\hline \multirow{4}{*}{$\begin{array}{l}\text { 9. Over the last week, how much } \\
\text { has your skin caused any sexual } \\
\text { difficulties? }\end{array}$} & Very much & $\square$ & \\
\hline & A lot & $\square$ & \\
\hline & A little & $\square$ & \\
\hline & Not at all & $\square$ & Not relevant $\square$ \\
\hline
\end{tabular}


Table 1: (Continued)

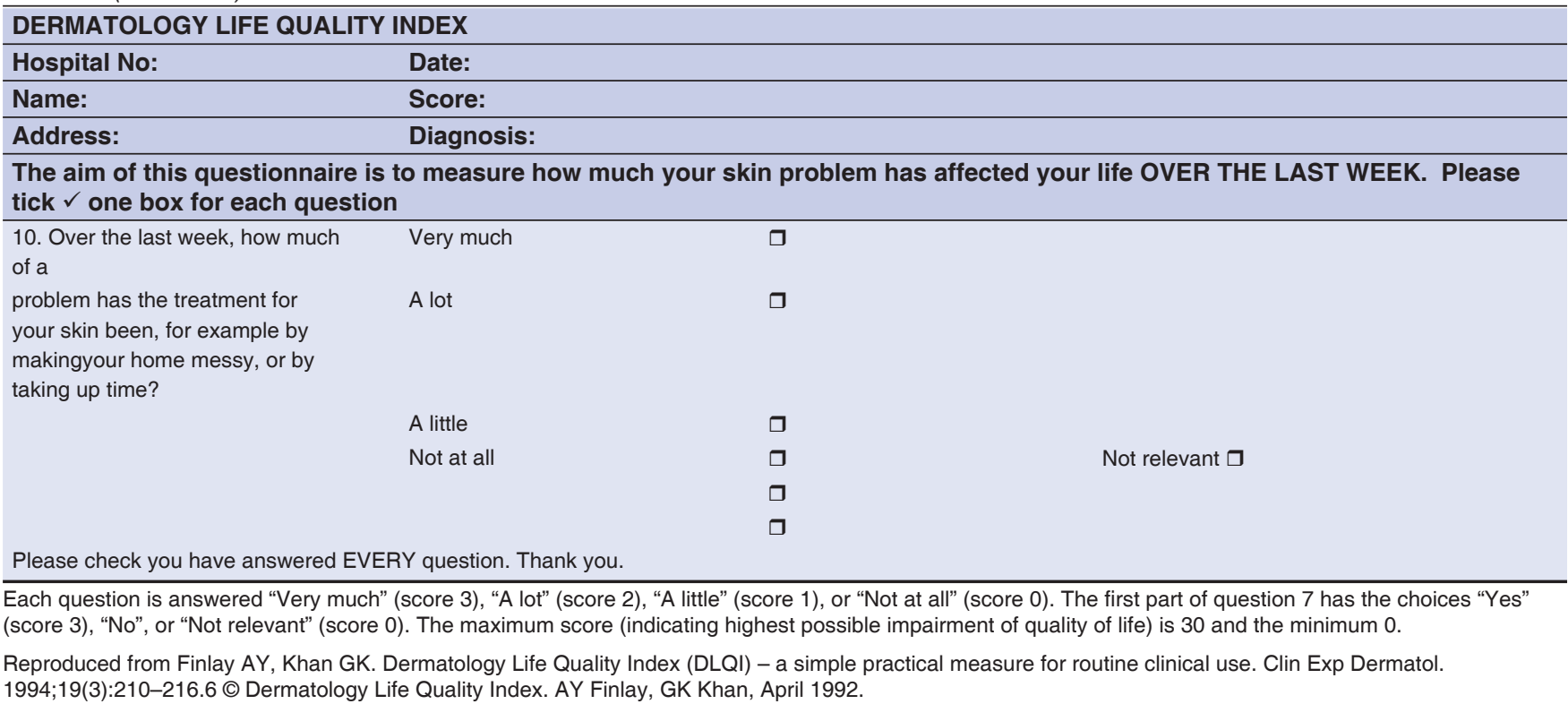

Table 2 : Clinical characteristics of the study population.

\begin{tabular}{|c|c|c|c|c|}
\hline $\begin{array}{l}\text { Clinical } \\
\text { characteristics }\end{array}$ & $\begin{array}{c}\text { Number } \\
\text { of } \\
\text { cases }\end{array}$ & $\begin{array}{l}\text { Mean } \\
\text { DLQI } \\
\text { score }\end{array}$ & $\begin{array}{l}\text { Student's } \\
\text { t test }\end{array}$ & $P$ value \\
\hline Age & & & 0.216 & 0.424 \\
\hline$<30$ yrs & 58 & 4.413 & & \\
\hline$>30 \mathrm{yrs}$ & 42 & 6.476 & & \\
\hline Marital status & & & 0.072 & 0.474 \\
\hline Single & 47 & 5.957 & & \\
\hline Married & 53 & 4.566 & & \\
\hline Education level & & & 0.697 & 0.278 \\
\hline Up to high & 26 & 3.769 & & \\
\hline $\begin{array}{l}\text {..school } \\
\text { College or more }\end{array}$ & 74 & 5.81 & & \\
\hline Duration of hair & & & 0.281 & 0.402 \\
\hline loss (months) & 41 & 5.170 & & \\
\hline$<12$ months & 59 & 5.3559 & & \\
\hline$>12$ months & & & & \\
\hline Alopecia severity & & & 0.163 & 0.442 \\
\hline Mild & 40 & 4.45 & & \\
\hline Moderate & 32 & 5.156 & & \\
\hline Severe & 28 & 6.607 & & \\
\hline
\end{tabular}

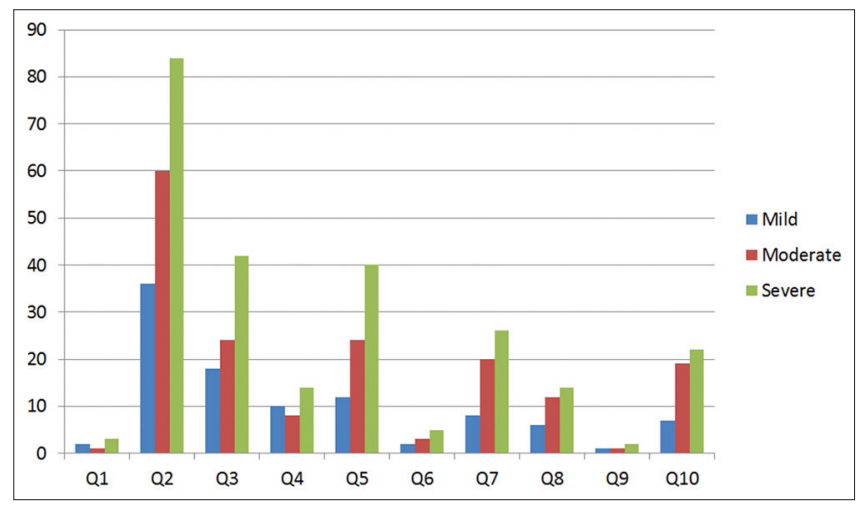

Figure 2: Total DLQI scores for different questions for different grades of hair loss. (DLQI - Dermatology Life Quality Index) self esteem, and worry [8]. Recently, a number of studies have also verified the psychosocial difficulties experienced by men with hair loss where it was seen that men with hair loss are generally seen by others as being significantly older, less physically and socially attractive, weaker, duller, and less potent than their peers [7]. It has been revealed that men who had more profound hair loss were more dissatisfied with their appearance and were more concerned with their older look than those with minimal hair loss and had lower self esteem. This effect cut across all age groups but was more prominent in the younger individuals. Physical appearance is extremely important to most young men, and early onset of hair loss can have a definite negative effect on self-image and self-esteem. Low self-esteem can cause significant difficulty for males especially when finding life partners and employment. This appears to be a result of the emphasis and importance of physical appearance and body image in social settings.

The present study had several limitations. First, all the patients in our study were recruited in dermatology outpatient centre and selection bias may, therefore, have affected the results. Also, the study sample was relatively small.

\section{CONCLUSION}

Patients with AGA have a significantly decreased quality of life. A higher DLQI score was seen in younger age, long standing hair loss and in severe grades of alopecia. AGA is associated with a lowered self esteem which in turn leads to functional consequences in 
societal and interpersonal interactions. It is important that physicians consider the psychosocial impact of AGA on different aspects of patient's lives.

\section{Statement of Human and Animal Rights}

All procedures followed were in accordance with the ethical standards of the responsible committee on human experimentation (institutional and national) and with the Helsinki Declaration of 1975, as revised in 2008.

\section{Statement of Informed Consent}

Informed consent was obtained from all patients for being included in the study.

\section{REFERENCES}

1. Kaliyadan F, Nambiar A, Vijayaraghavan S. Androgenetic alopecia: An update. Indian J Dermatol Venereol Leprol. 2013;79:613-25.
2. Hunt N, McHale S. The psychological impact of alopecia. BMJ: Br Med J. 2005;331:951.

3. Poot F. Psychological consequences of chronic hair diseases. Rev Med Brux. 2004;25:A286-8.

4. Zhang M, Zhang N. Quality of life assessment in patients with alopecia areata and androgenetic alopecia in the People's Republic of China. Patient Pref Adher. 2017;11:151.

5. Gupta M, Mysore V. Classifications of patterned hair loss: a review. J Cutan Aesthet Sur. 2016;9:3-12.

6. Williamson D, Gonzalez M, Finlay AY. The effect of hair loss on quality of life. J Eur Acad Dermatol Venereol. 2001;15:137-9.

7. Han SH, Byun JW, Lee WS, Kang H, Kye YC, Kim KH, et al. Quality of life assessment in male patients with androgenetic alopecia: result of a prospective, multicenter study. Ann Dermatol. 2012;24:311-8.

8. Williamson D, Gonzalez M, Finlay AY. The effect of hair loss on quality of life. J Eur Acad Dermatol Venereol. 2001;15:137-9.

Copyright by Mrinal Gupta. This is an open-access article distributed under the terms of the Creative Commons Attribution License, which permits unrestricted use, distribution, and reproduction in any medium, provided the original author and source are credited

Source of Support: Nil, Conflict of Interest: None declared. 